\title{
Lacan, revolução e liquidação da transferência: a destituição subjetiva como protocolo de emancipação política
}

VLADIMIR SAFATLE ${ }^{I}$

$\mathrm{E}$ M 1967, Lacan apresenta um texto fundamental sobre psicanálise e política, a saber, Proposição de 9 de outubro de 1967 sobre o analista da Escola. Diante da necessidade de justificar o funcionamento de uma instituição que ele próprio criara, a Escola Freudiana de Psicanálise, Lacan apresenta um texto de clara conotação política cujo eixo central será a reflexão sobre a estrutura da transferência. Tal escolha não poderia ser de outra forma, pois se é verdade que a psicanálise pensa os processos de constituição de laços sociais a partir de dinâmicas de identificação, se é fato que não é possível haver laço social sem alguma forma de identificação, já que a identificação visa explicar a dimensão produtiva do poder, ou seja, a maneira com que o poder produz a vida psíquica, mobiliza afetos e demandas de amor, constituindo os sujeitos aos quais ele se relaciona, então será a tematização da transferência que pode nos abrir as portas à compreensão dos modos de abandono da dominação. Nesse sentido, há uma reflexão sobre processos de emancipação que nasce como saldo necessário da transferência. Levando em conta o exercício do poder através das identificações, toda a emancipação possível terá a forma de uma liquidação da transferência, com suas questões ligadas ao destino da experiência do saber, à destituição subjetiva e à dejeção do analista.

Pois há de fazer uma distinção aqui. As identificações mostram como as relações sociais são, necessariamente, relações de poder e repetição. Ao me identificar com algo ou alguém, assumo o desenvolvimento implícito próprio àquilo com o qual me identifiquei, as estruturas da minha vida psíquica e seus desenvolvimentos serão produzidos por aquilo com o qual me identifiquei. Desde o estádio do espelho, Lacan insiste que se identificar com uma imagem é internalizar o princípio de desenvolvimento que ela contrai, é constituir-se no interior da história que ela representa. Ou seja, toda identificação é um exercício de poder. No entanto, nem todas as relações de poder são relações de dominação. Pois podemos lembrar como a sustentação dos processos identificatórios se dá, em última instância, por aquilo que nem eu nem o Outro é capaz de dominar. 
Há algo que circula e se sustenta nos processos identificatórios que não pode ser compreendido como exercício de uma dominação. Pois tais processos se produzem sustentando-se em algo que ultrapassa toda vontade dos sujeitos e que Lacan tematiza através de sua teoria dos objetos $a$, algo cujo circuito próprio sempre insiste no interior das relações de poder e que faz que tais relações sejam, no fundo, instáveis, sempre prontas a se inverterem, a se derivarem. Insistamos em um ponto fundamental: uma relação de dominação é a expressão da submissão da minha vontade à vontade do Outro, mas há aquilo que permite ao poder circular e que não é nem minha vontade, nem a vontade do Outro. Algo que produz vínculos sem ser a expressão da vontade de um sujeito, mas expressão de uma dinâmica inconsciente de afetos. O poder circula expropriando algo que pode depô-lo.

Tiremos, por exemplo, as consequências de uma afirmação como:

Assim funciona o i(a) do qual o eu e seu narcisismo imaginam fazer o casulo deste objeto $a$ que faz a miséria do sujeito. Isto porque o (a), causa do desejo, por estar a mercê do Outro, angustia o sujeito na ocasião, vestindo-se contrafobicamente da autonomia do eu, como faz o caranguejo ermitão de toda carapaça. ${ }^{1}$

Lacan está a dizer que o eu ideal, que sustenta processos identificatórios responsáveis pela constituição imaginária do eu através de relações narcísicas, sustenta-se por apoiar-se em objetos $a$, por tentar retirar a angústia que eles produzem (lembremos, em Lacan, a angústia tem um objeto) fortalecendo o discurso da autonomia do eu. Uma autonomia da vontade que aparece como discurso de defesa contra a fobia resultante da descoberta de que aquilo que nos constitui em nossa identidade, as imagens que nos constituem, só são desejantes na medida em que elas trazem algo que pode dissolvê-las, algo cuja dinâmica é marcada pela deriva. Por isso podemos dizer: o que sustenta a reprodução material da vida psíquica, o que permite o exercício constituinte das relações de poder é algo que, ao mesmo tempo, pode dissolver as próprios relações de poder. E se o poder consegue controlar a circulação desses objetos que nos descentram, é porque ele sabe que $o$ reconhecimento de si nesses objetos nos angustia. O poder sabe que a liberdade nos angustia, ao mesmo tempo que ela nos atrai. Se sujeitos aceitam a servidão é porque eles temem a angústia que a liberdade produz e um dos exercícios fundamentais que a análise pode fornecer ao exercício da liberdade é levar o sujeito a depor suas defesas contrafóbicas. É mostrar que a angústia da liberdade não vem da possibilidade transcendente de tudo fazer e desejar, mas da realização de que somos agidos por uma causalidade exterior que, como dizia Lacan, é algo em nós mais do que nós mesmos.

É essa instabilidade das relações de poder que a transferência permite circular, é dessa instabilidade que ela é feita e desfeita. E insistiria que esse movimento duplo é fundamental. Compreender a transferência é compreender como ela é feita e desfeita, é compreender como sua liquidação é a abertura do 
sujeito àquilo que poderíamos chamar de relações de poder sem dominação. Daí uma questão política central para Lacan, a saber, a politica exige instituições nas quais a liquidação da transferência possa ser reconbecida. A transferência não é um fenômeno existente apenas em situações analíticas, ela existe em todo lugar onde há poder e identificação. Não há relação à autoridade que não produza modalidades de laço transferencial. Por isso, seu destino pode nos dizer algo de fundamental a respeito dos processos de emancipação.

Nesse sentido, a função da Escola pensada por Lacan era basicamente reconhecer sujeitos que passaram pela liquidação da transferência, que por isso deixaram para trás uma forma de sujeição que se expressava não apenas na suposição de um saber ao Outro, mas na suposição de um saber que me constituiria, que definiria os modos de minha relação a mim mesmo, um saber que produziria meus modos de controle, de autonomia, de deliberação. Por essa razão, esse reconhecimento não era apenas a garantia para a constituição de vínculos sociais não mais assombrados por relações de sujeição. Era a possibilidade de emergência de vínculos capazes de transformar sujeitos.

Afinal, Lacan compreendia perfeitamente que, se alguém entra em análise, é porque há uma suposição de saber sobre a verdade do seu desejo. Essa suposição de saber não é apenas uma curiosidade cognitiva, um querer se conhecer melhor, mas é uma expectativa de reconfiguração das estrutura da prática e do cuidado a partir de um saber sobre si mesmo. No entanto, esse saber suposto será destituído, não pela simples constatação da ignorância do analista ou pela ineficácia do discurso analítico, mas pela emergência da circulação de um objeto que sustentava a relação e que esteve, até então velado. Isso nos explica por quê, no discurso do analista, é o objeto que ocupa o lugar de agente. Nesse momento, revela-se ao sujeito como sua ligação à suposição de saber era, na verdade, um vínculo a um objeto que lhe causava, que lhe retirava de si. O saber analítico realiza-se ao se destituir.

Um exemplo disso é dado pela leitura lacaniana do diálogo entre Alcebíades e Sócrates em O banquete. De certa forma, a leitura de Lacan faz de Sócrates o primeiro analista, assim como faz da resposta de Sócrates ao desejo de Alcebíades a primeira lição de manejo da transferência que teríamos conhecido. Tal escolha tem uma clara conotação política. Nos diálogos de Platão, Alcebíades não é apenas aquele que não sabe como governar a si mesmo por ser descontrolado, servo de seu próprio desejo. Ele é aquele que espera poder governar a polis, governar os outros. De certa forma, Sócrates é aquele que tenta mostrar a Alcebíades como ele não será capaz de governar a cidade enquanto não for capaz de governar a si mesmo. No entanto, o governo de si nesse contexto não se confunde, ao menos para Lacan, com uma dominação de si com suas dinâmicas de controle e autolegislação. Na verdade, podemos mesmo dizer que governar a si mesmo é indissociável da capacidade de reconhecer: "este resto que como determinando a divisão do sujeito, o faz decair de seu fantasma e o destitui como 
sujeito". ${ }^{2}$ Se Sócrates mostra algo a Alcebíades é como não haverá governo de si enquanto ele não for capaz de se confrontar com o objeto que causa seu desejo, mas confrontá-lo em um ponto no qual tal relação ao objeto se constitui em um espaço onde o fantasma decaiu e o próprio sujeito foi destituído.

Por isso, Lacan insiste na maneira com que Sócrates afirma que Alcebíades se engana a respeito de seu desejo, pois apesar de suas demonstrações e louvores não é exatamente ele, Sócrates, que Alcebíades deseja, mas os agalmatas que ele porta. O que Sócrates faz, pois, é uma operação de separação, na medida em que ele tenta mostrar a Alcebíades uma distância entre $I$ e $a$, entre o ideal do Eu e o objeto que o sustenta. Ao expor tal distância, Sócrates produz uma espécie de curto-circuito no sistema de identificações que sustentava a posição de Alcebíades, já que o ideal do Eu não aparece mais, como aparecia outrora, como o ponto de transcendência necessário à afirmação da emancipação em relação aos objetos imaginários. Ele aparece como uma vestimenta que sustenta o sujeito por impedi-lo de se confrontar com um objeto sem lugar que, no entanto, nos causa, age em nós e nos constitui.

Por isso, faz-se necessário insistir que, se o saber na transferência é saber suposto sobre meu desejo e o que lhe causa, o processo analítico visa extrair o objeto que causa meu desejo das sendas do saber. Sócrates diz nada saber a respeito das coisas do amor, o que não significa que ele não saiba o que fazer com tais coisas. Significará apenas que tal fazer não se orienta como uma deliberação, não funda um saber partilhado que se inscreve como lugar dentro de uma estrutura simbólica. Ele é uma forma de abertura que pressupõe uma destituição de domínio, uma forma de reconhecimento de uma causalidade exterior a respeito da qual não faz mais sentido procurarmos nos defender. Lacan fala então uma operação de "afrontar a verdade", distinta da operação de exercício de um saber. Aqui, essa distinção entre saber e verdade é fundamental.

Ele mesmo reconhece que isso parece inicialmente significar a impossibilidade de constituir qualquer forma de laço social: "A destituição subjetiva inscrita no ticket de entrada [...] não seria provocar o horror, a indignação, o pânico, ou mesmo o atentado, em todo caso dar o pretexto à objeção de princípio?”. ${ }^{3}$ Pois o que pode ser um laço constituído a partir de uma liquidação da transferência que parece impossibilitar toda identificação simbólica, que não pode mais mobilizar produção fantasmática alguma, isto a ponto de Lacan afirmar:

Nesta viragem na qual o sujeito vê vacilar a segurança fornecida pelo fantasma, onde se constitui para cada um sua janela para o real, o que se percebe é que a tomada do desejo não é outra coisa que a de um desser. Neste desser se desvela o inessencial do sujeito suposto saber, no que o psicanalista por vir se vota ao agalma da essência do desejo, prestes a pagá-lo por se reduzir, ele próprio e seu nome, ao significante qualquer. ${ }^{4}$

É dessa forma que Lacan descreve o processo de término da transferência. Notemos inicialmente como se trata de decompor a segurança que o fantasma 
fornece por ser uma janela para o real, ou seja, por enquadrar o real em uma certa distância e operação. Há de aproximar o real do sujeito e é isso que ocorre no final de uma transferência. Quando tal segurança produzida pelo fantasma vacila, o desejo se revela como não sendo outra coisa que um desser. Sendo o desejo o ser do sujeito, esse ser se revela aqui um desser. Não exatamente alguma forma de reinscrição do sujeito na segurança ontológica de um ser pensado como normatividade, como necessidade, mas a deriva de uma desapropriação. O desejo pode então se mostrar como a deriva de uma desapropriação. Essa viragem do ser ao desser é própria da dessuposição do saber do analista. Ou seja, na análise, o analista passa por um desser, o que pressupõe uma angústia e dejeção, e o analisando passa por uma destituição subjetiva, o que pressupõe certo desamparo.

Essa destituição está descrita através de uma mudança na estrutura dos processos de reconhecimento. Pois temos agora não o reconhecimento de si não em outro sujeito, mas em um objeto. Tal reconhecimento é feito de forma tal a reduzir o nome do sujeito a um significante qualquer, ou seja, seu nome, aquilo que estabelece relações de filiação e transmissão, aquilo que porta a marca de sua inscrição no horizonte de uma constelação familiar, decai à condição de significante qualquer, isso no sentido de uma inscrição meramente contingente, sem lugar no interior de uma cadeia de necessidades. Ou seja, a reinscrição simbólica que a interpretação analítica pode produzir devido à mobilização dos quadros de relação próprios ao complexo de Édipo e seu horizonte normativo é deposta para que o nome apareça como significante qualquer. Assim, a contingência se revela no interior de um desejo que abre uma clareira para fora de toda segurança ontológica.

Mas, há ainda uma questão central: por que esse processo não seria apenas um processo depressivo? O que faz dele um processo, ao contrário, de afirmação da liberdade e da emancipação? E como será possível constituir laços sociais após uma experiência dessa natureza?

\section{Transferência e emancipação}

Para responder tais questões, comecemos por nos perguntar sobre como se liquida um processo transferencial. É claro que essa pergunta só poderá ser respondida em um nível genérico, já que os caminhos de uma análise são sempre singulares. $\mathrm{O}$ que não significa que tal genericidade seja desprovida de importância e interesse, que ela não revele traços de estrutura. Diremos então que a transferência é liquidada quando ocorre aquilo que Lacan chama de "ato analítico". Um ato que pode responder de outra forma a respeito de problemas gerais de emancipação.

Lembremos inicialmente de algumas considerações gerais sobre os processos de emancipação como horizonte normativo para as lutas políticas. Conhecemos a tendência tradicional em ordenar as discussões sobre emancipação a partir da noção reguladora de maturidade, como se estivéssemos a generalizar, para a esfera da vida social, consequências da distinção entre minoridade e maioridade. 
Dessa forma, lutas políticas orientadas por expectativas de emancipação seriam lutas para realizar formas de reconhecimento de si que permitiriam o desenvolvimento enquanto indivíduo capaz de deliberação própria e afirmação de si.

No entanto, há de insistir que essa forma de pensar a emancipação não nos permite distingui-la da sujeição a padrões disciplinares de comportamento socialmente exigidos e necessários, padrões esses normalmente enunciados como expressão efetiva da autonomia. Sair da minoridade pode ser compreendido como resultado da internalização de sistemas de julgamento e de ação socialmente aceitos como próprios àqueles sujeitos considerados imputáveis e responsáveis. Nesse contexto, corre-se o risco de não podermos mais estabelecer distinções minimamente operativas entre emancipação e mera adaptação social a padrões jurídicos de imputabilidade, ou ainda entre reconhecimento, enquanto instauração de modos de existência até então impredicados, e recognição, como confirmação de potencialidades postas pelo modo atual de existência. Assim, uma condição de socialização historicamente definida e juridicamente organizada acaba por se transformar em horizonte ontologicamente estável de regulação das formas de vida. No entanto, a sua maneira a noção de ato analítico nos permite ver a emancipação aparecer como possibilidade do sujeito emergir enquanto potência normativa capaz de produzir singularizações. Mas para tanto há uma modificação estrutural na noção de agência que precisa ocorrer.

A esse respeito, lembremos como, ao definir sua noção de ato analítico, Lacan afirma que ele estaria fundado em uma "estrutura paradoxal vinda do fato do objeto estar nele ativo e o sujeito subvertido". ${ }^{5}$ Uma subversão que é inscrição da posição do sujeito no real. Voltamos a esse ponto pois tal ideia de um ato capaz de inscrever o sujeito no real é central. Ela implica que, ao produzirem um ato, sujeitos agem a partir do que coloca em colapso a ordem simbólica. Por isso, eles perdem sua inscrição anterior na ordem simbólica e na ordem do saber que os constituíram. Essa é a razão pela qual, do ponto de vista clínico, o conceito de ato analítico acaba por reconfigurar globalmente os processos de intervenção analítica ao secundarizar os mecanismos de simbolização através da inscrição significante produzida pela interpretação. A partir de agora, a análise não irá procurar, através da interpretação, fornecer a inscrição dos sujeitos no interior de um quadro regulado de conflitos e filiações. Ela irá confrontar os sujeitos a um ato que os destituem de tal lugar.

Isso nos explica por que, no dispositivo do ato analítico, vincula-se uma força de dissolução e uma operação de instauração, e toda sua complexidade está exatamente na compreensão desse duplo movimento. Não é possível pensar processos de instauração sem responder a pergunta sobre como se realiza dissoluções. Pois há dissoluções que são apenas degradações da ordem anterior, ou se quisermos, mera passagem ao ato, mera fascinação pela aniquilação que retira do ato toda possibilidade de reconhecimento. Por isso, as formas clássicas da passagem ao ato são vinculadas ao suicídio. 
No entanto, há dissoluções e desabamentos que são pressões de novas orientações e lembraria que uma das questões fundamentais para a reflexão sobre a ação política é: como fazer ordens desabarem? Pois, e isso a experiência das revoluções no século XX nos mostrou, ordens podem se perpetuar mesmo após sua queda, ou melhor, elas podem se perpetuar exatamente por terem caído e por passarem a um modo implícito de existência, ao invés de um modo explícito de ordenamento. Elas podem então ressurgir, como uma reincidência que ressurge quando menos esperamos ou elas podem continuar operando em um estrato subterrâneo, paulatinamente corroendo a nova ordem até ela se tornar irreconhecível. Por isso, a questão do ato político como um processo de dissolução é de suma importância. O que toda política revolucionária sempre soube, basta lembrar a problemática de Marx a respeito da dissolução do Estado. Não se dissolve o Estado para a abertura a uma sociedade de associações de sujeitos livres sem conquistá-lo e transforma-lo até que todos seus modos de reprodução se transfigurem (essa era inclusive a necessidade da temática da chamada "ditadura do proletariado"). De outra forma, ele poderá perpetuar-se em silêncio, entrar em um modo implícito de existência.

\section{Uma certa revolução}

Tal discussão nos remete à potência de negação própria a todo ato. Em vários momentos, Lacan aproxima o ato analítico de uma certa leitura possível do conceito político de revolução. No entanto, há de fazer uma distinção aqui. Em várias circunstâncias, Lacan insistia que "revolução" significa normalmente, como sabemos a respeito dos movimentos astronômicos, "voltar ao mesmo lugar". Ao comentar a revolução copernicana, tão usada como metáfora de mudança epistêmica na filosofia (Kant e a crítica como revolução copernicana) e mesmo na psicanálise (Freud e a revolução copernicana do inconsciente), Lacan se perguntava: "o que há de revolucionário no recentramento do mundo solar em torno do Sol?". ${ }^{6}$ Maneira de afirmar que não havia mudança alguma através da conservação da hierarquia, da unidade e da centralidade que a noção de movimento esférico enquanto forma celeste perfeita representava. A verdadeira revolução encontrava-se no advento do movimento elíptico, ou seja, da noção de dois centros enquanto forma dos movimentos celestes. No que se vê que a revolução, se não quiser ser um retorno ao mesmo lugar, é indissociável de uma mudança na estrutura do saber, não apenas nos lugares que cada elemento ocupa no interior de uma estrutura dada, não apenas nos detentores do saber e do poder. Ao dizer isso, Lacan visava o modo de circulação do discurso sobre a revolução nos meios intelectuais dos anos sessenta.

Em seu lugar, Lacan procura pensar a revolução que uma experiência analítica realmente implica fazendo apelo à poesia. Lembremos a esse respeito um poema caro a Lacan que lhe aparecia como expressão da "fórmula geral do ato", trata-se de A uma razão, de Arthur Rimbaud: 
Um bater de seu dedo contra o tambor descarrega todos os sons e começa a nova harmonia

Um passo seu é o levante de novos homens e os põe em marcha

Tua cabeça se vira: o novo amor!

Tua cabeça se volta: o novo amor!

"Muda nossos destinos, alveje as pragas, a começar pelo tempo", cantam essas crianças.

"Cultiva não importa onde a substância de nossas fortunas e desejos", te suplicam.

Vinda de sempre, quem irá contigo por toda parte.

Primeiro, há de salientar que a fórmula geral do ato analítico seja dada por um poema. Pois se trata de aproximar ato e emergência de outro regime de partilha da linguagem que se encontra expresso na forma do poema. Se a linguagem aparece aqui em posição fundamental é por ela decidir a forma da experiência, a dinâmica de nossas gramáticas de afetos, a estrutura das nossas sensibilidades. Não há revolução efetiva sem uma transformação na capacidade de enunciação da linguagem. A esse respeito, lembremos uma discussão de Stalin a respeito de a linguagem não ser uma superestrutura, já que ela não poderia ser mudada ao modificarmos as relações de produção:

$\mathrm{O}$ que poderia ser a necessidade para tal revolução linguística se demonstrarmos que a linguagem existente e sua estrutura são fundamentalmente adequadas às necessidades do novo sistema? A antiga superestrutura pode e deve ser destruída e substituída por uma nova no curso de alguns anos, a fim de dar livre curso ao desenvolvimento das forças produtivas da sociedade, mas como poderia uma linguagem existente ser destruída e uma nova construída em seu lugar no curso de alguns anos sem causar anarquia na vida social e sem criar a ameaça de desintegração da sociedade? Quem a não ser um Dom Quixote poderia dar a si mesmo tal tarefa? ${ }^{7}$

Stalin, que sabia bem o que significa assassinar uma revolução, recusa que a linguagem seja uma superestrutura porque ela não deve ser nem o veículo nem o resultado de um processo revolucionário. Ela deve permanecer tal e qual, sob o risco de desencadear anarquia e desintegração. No entanto, há de perguntar que tipo de revolução é esse que vê as instaurações no campo da linguagem como algo fora de seu escopo. Pois afirmar que a linguagem não se modifica é a maneira mais segura de afirmar que uma revolução não altera aquilo que aparece como a condição prévia (ao menos para os sujeitos falantes) de toda experiência possível. Para a restauração, é fundamental afirmar que a linguagem desconhece dinâmicas políticas por ela expressar a "totalidade" da sociedade. No entanto, digamos que, se Stalin houvesse lido Nietzsche, ele saberia que: "nunca nos desvencilharemos de Deus enquanto acreditarmos na gramática". Esta era uma forma astuta de afirmar haver uma metafísica implícita na gramática e o que faz uma revolução é dissolver esta metafísica implícita que orienta os processos mais elementares de nossa forma de vida. É com isso em mente que podemos nos voltar ao poema de Rimbaud e a seu uso por Lacan. 
Primeiro, lembremos do título: "a uma razão". A fórmula geral do ato é vinculada a um poema intitulado: "a uma razão". O que mais se evidencia aqui é a ideia de "uma razão", e não de "a razão". Como se fosse questão de dizer "cada um tem sua razão". Mas uma frase dessa natureza normalmente parece significar: "não há razão alguma, pois cada um tem a sua". Não havendo razão alguma, não há ratio, não apenas no sentido de não haver medida comum, mas principalmente no sentido de não haver implicação genérica. Não havendo a razão, parece não haver nada que nos implique genericamente, nada que nos forneça um campo, parece haver apenas uma fala, mais uma fala, mais uma fala.

No entanto, o poema expressa exatamente o inverso dessa ideia. Como se a singularidade da experiência que me faz o corpo no qual se irrompe uma razão fosse uma experiência irrecusável para todo e qualquer. Como se o que é desvelado só fosse a abertura de um comum ainda fora do mundo. Nesse sentido, lembremos como "raison" tem em seu interior "son" que aparece no poema quando o bater do tambor descarregar "tous les sons". Há a infinitude de todos os sons nessa razão que emerge. Nesse sentido, se o artigo indefinido "uma" singulariza, tal singularidade indica apenas a corporeidade da experiência do que se resolve em todos os sons, o que exige também todos os ouvidos, o que mimetiza todas as vozes.

É claro como o poema começa com um horizonte de guerra e música, com se a verdadeira guerra fosse a transformação da linguagem em música. Ele começa com um toque de tambor, como quem anuncia a criação ao romper o silêncio com um gesto sonoro, normalmente seco, sem ressonância, mas agora essa ausência de ressonância é o advento de uma nova harmonia produzida por todos os sons. Mas notem um ponto importante aqui. Todos os sons tocados juntos só podem produzir uma massa sonora do tipo cluster, nunca fornecer uma nova harmonia. Um toque que descarrega todos os sons pode ser visto, na verdade, como um som capaz de produzir qualquer harmonia, um pouco como a substância de nossa fortuna e desejos que pode ser cultivada não importa onde, como o que virá contigo por toda parte. Ou seja, o que se fala aqui é de uma relação (pois a harmonia é necessariamente uma relação) sem restrição, sem perda, que potencialmente pode operar em um tempo e um espaço que não conhecem mais a finitude das determinações. E assim que a irrupção da guerra com suas mudanças e domínios se transmuta em música, o poema produz a irrupção do novo: novos homens, novo amor. Um novo amor que precisa ser repetido, que não se diz apenas uma vez, que precisa fazer a cabeça retornar em direção a um chamado mais uma vez. Como se fosse o caso de lembrar que atos revolucionários são repetições, que este tempo das emergências se abre ao se repetir.

Que seja o amor aquilo que deve ser repetido, que na verdade o amor seja a cena de uma repetição, seja o que permite a repetição existir em sua força de transformação, nos mostra como é no interior deste novo amor que emerge a razão da qual fala Rimbaud. Tal como a razão, o amor é questão de relação e de 
existência sob relação. Como ele dirá em outro poema, Génie: "amor, medida perfeita e reinventada, razão maravilhosa e imprevista". Pois haverá um tempo próprio, uma destituição própria ao amor e à dispersão de seu ato. Este tempo próprio funda outra razão, como Lacan percebeu bem ao afirmar: "o amor, neste texto, é o signo apontado como tal, de que se troca de razão". ${ }^{8}$

$\mathrm{E}$ ao produzir esta repetição que denuncia um desejo de instauração e duração, o poema se abre a um canto. Um canto de crianças cuja música traz os destinos que devem mudar e o tempo que deve ser alvejado como uma praga para que ele se abra ao que vem de sempre, ou seja, ao que vem do que suspende a própria ordem do tempo. Crianças que não apenas cantam, mas suplicam porque sentem a urgência de que os desejos sejam cultivados em um lugar fora do lugar, em um "não importa onde" fora do mundo tal como agora se compõe e divide.

Um ato é sempre a irrupção de outro tempo e outro espaço, esta é sua função: permitir que o desejo seja cultivado em outro tempo e em outro espaço, que quebra a hierarquia dos lugares, que dessacraliza as distâncias. Por isso, o poema só poderia terminar em uma frase sem sujeito: "Vinda de sempre, quem irá contigo por toda parte". Pois o que vem de sempre e por toda parte inicia-se por dissolver a unidade de todo sujeito. $\mathrm{O}$ que não pode ser diferente para alguém, como Rimbaud, que em uma carta a Izambard dirá: "É falso dizer: eu penso; deveríamos dizer: pensam-me".

Nesse sentido, não é por acaso que Lacan escolhe Rimbaud para fornecer uma fórmula geral do ato analítico. Trata-se do poeta que falará de um tempo de revoluções, que escreverá poemas sobre a comuna e as batalhas de emancipação popular, que abandonará o poema versificado, que fará a linguagem se aproximar de um sistema de cores devido ao trabalho fonético com as vogais, ou seja, que produzirá uma nova aisthesis na linguagem e em sua força de expressão, explorando dimensões significantes que se elaboram para além dos modos meramente semânticos de determinação do sentido. Um "desregramento de todos os sentidos", como dirá o próprio Rimbaud que é advento de novos princípios construtivos. Lembremos como o poema "A uma razão" foi escrito entre 1872 e 1873, ou seja, logo após a comuna. O que dá uma expressão bastante concreta de quem são esses novos homens que se levantam e se põem em marcha expressando uma nova harmonia.

Há de ter isso em mente quando ouvirmos Lacan dizer que: "o ato tem lugar em um dizer e ele modifica o sujeito", ou ainda "o ato destitui em seu fim o próprio sujeito que ele instaura". ${ }^{9}$ Isso demonstra como o ato analítico é solidário de um dizer que, ao invés de meramente exteriorizar o sujeito, modifica-o em uma paradoxal instauração destituinte. Essa posição paradoxal talvez explique por que "o ato se realiza da melhor forma ao fracassar", o que não significa que todo ato seja um fracasso. Há um tipo de fracasso que é resultado da pressão da produtividade do desejo em direção a novas formas, um pouco como os atos 
falhos são um fracasso da força de determinação da linguagem ordinária. Pois há de sentir a linguagem atual fracassar, confessar sua impotência e transmutar suas categorias. O que, fossemos Lacan, diríamos da seguinte maneira: "Minha prova toca o ser apenas ao fazê-lo nascer da falha que produz o ente por se dizer". ${ }^{10}$

É neste ponto que podemos entender a implicação política do conceito de ato analítico. Ele nos permite pensar a noção política de revolução para além de sua submissão a uma dinâmica de restauração. O que só é possível pelo ato nos mostrar mais claramente qual a verdadeira dimensão de transformação que uma ação revolucionária deve produzir. Ela se vincula à modificação da estrutura saber/poder. Mas, e este é um ponto decisivo, isso não implica simplesmente deslocar o saber anteriormente pressuposto no Outro para um saber agora presente na consciência do sujeito. Não significa reapropriar-se do saber. Pois esse deslocamento seria apenas a reiteração de um mesmo regime de saber e de ação, só que agora disponível à consciência. De nada adiante louvar a prática se essa prática ainda é dependente da mesma gramática de saber que havia nos sujeitado. Uma gramática composta por ideais de autonomia, deliberação, escolha e decisão que remetem necessariamente ao modo de representação da consciência. Pouco importa quem realmente age, quando sempre se age a partir da mesma gramática. Em todos os casos, é a gramática que age, são os sistemas de regra e existência que agem. Uma prática emancipada não é o resultado da transferência de uma saber que supúnhamos no outro e que agora nos o reapropriamos. A emancipação não é uma transferência de saber que nos permitiria recuperar a enunciação do saber para nós, que nos permitiria melhor deliberar conscientemente. Como se tivéssemos agora a posse de uma saber nos foi negado. A emancipação é, antes, uma deposição do saber. Notemos o sentido de uma afirmação decisiva como:

Assim o ser do desejo reencontra o ser do saber para renascer nisto em que eles se juntam em uma tira feita de um lado só no qual se inscreve uma falta só, esta que sustenta o agalma. ${ }^{11}$

Desejo e saber se encontram como dois lados de uma banda de Moebius se encontram. Eles passam um no outro e ao passar um no outro, passagem que se dá apenas à condição de assumirem uma torção, eles fazem dessa passagem a inscrição de uma falta, que não é uma falta simplesmente ligada à incompletude ou à subjetivação da castração compreendida como assunção da finitude, mas que é emergência de um objeto que não se reduz a ser aquilo que uma cadeia significante pode representar. Quando uma saber do desejo é possível, é só através de uma torção que, do ponto de vista da configuração atual do saber, é uma falta.

Mas insistamos em um ponto fundamental. Se algo aparece em falta, é porque eu não o tenho. Se a junção entre desejo e saber inscreve uma falta estrutural é porque ela aponta para algo que nunca posso ter, que nunca se colocará sob o signo da minha posse, e essa é exatamente uma das características principais dos agalmata: os sujeitos não os tem, eles os portam, o que é algo 
totalmente diferente. Essa é uma maneira de dizer que a dessuposição de saber que é condição para a liquidação da transferência tem algo de assunção de uma outra fala, de uma outra relação à linguagem, a uma linguagem que não apareça exatamente como minha, de um saber que não reforça a ilusão de minha propriedade e de meu domínio. Daí afirmações como:

Tudo o que é do inconsciente se desdobra apenas a partir dos efeitos da linguagem. É algo que se diz, sem que o sujeito aí se represente, nem que ele aí se diga - nem que ele saiba o que ele diz. ${ }^{12}$

Mais do que ser estruturado como uma linguagem, o inconsciente é uma fala que depõe o próprio falar de si do sujeito. Ele é a emergência de uma linguagem que não aparece mais como minha. Não apenas porque suas enunciações estão submetidas ao involuntário, não são comandadas por mim, mas principalmente porque essa não é mais a linguagem do sentido e da reinstauração da propriedade produzida pelas dinâmicas de sentido. Ela é a linguagem de um acontecimento da verdade.

\section{A religião do sentido}

É claro que essa noção de sentido com a qual Lacan trabalha tem sua especificidade. Afinal, o que pode ser uma linguagem que não é uma linguagem do sentido, mas uma linguagem de um acontecimento da verdade, como Lacan pressupõe ao falar do inconsciente? Dentre as várias formas de discutir este problema complexo, insistamos em uma que expõe a dimensão política deste debate. Lembremos quando Lacan afirma, em um texto no qual é questão do ato político de dissolução de uma instituição que ele próprio criou:

A Internacional, já que este é seu nome, se reduz ao sintoma que ela é daquilo que Freud dela esperava. Mas não é ela que pesa. É a Igreja, a verdadeira, que sustenta o marxismo por lhe fornecer sangue novo... um sentido renovado. Por que não a psicanálise, quando ela se volta ao sentido? Não digo isto por uma persiflagem vã. A estabilidade da religião vem do fato que o sentido é sempre religioso. ${ }^{13}$

Essa é a maneira lacaniana de dizer que o verdadeiro problema político com o qual devemos lidar é a recrudescência da dimensão teológico-política do poder. Sendo a religião uma forma de sustentar vínculos sociais através da redução da dimensão política das demandas à demanda de amparo, de constituição de autoridade através das figuras do poder pastoral, afirmar que o sentido é sempre religioso significa dizer que a psicanálise deve ser capaz de fazer emergir o que não se ampara por não ser pensável no interior de relações de necessidade, de confirmação do originário, do destino teleológico, da unidade substancial da redenção. Lacan não teme em falar aqui da religião, de um certo marxismo e da burocratização dos vínculos sociais através de uma Internacional (no caso, a IPA) que se sustenta apenas por seu medo do ato analítico.

Esses casos demonstram que, para Lacan, as operações de produção de sentido são produções de relações de necessidade estruturadas a partir de di- 
nâmicas teleológicas no interior das quais apenas se desdobra a expressão de uma origem em seu processo de realização destinal. Nesse contexto, sentido só pode aparecer como uma relação de necessidade garantida por um fundamento situado na origem. O sentido reinstaura o que foi perdido, ele cura fazendo-nos retornar a um fundamento original. Assim, a principal contraposição é entre sentido e acontecimento. Uma contraposição a respeito da qual Lacan insiste em suas consequências políticas. Se Lacan critica o marxismo aqui é por compreender sua teoria da revolução dependente de uma escatologia histórica na qual o proletariado aparece como sujeito-objeto enfim reconciliado. Nessa escatologia, todo acontecimento é anulado diante do peso de um tempo que não é outra coisa que a projeção de uma realização irresistível do progresso. Essa não é a única leitura que podemos fazer da teoria da revolução em Marx. No entanto, é ela que Lacan adota nesse momento.

Mas diante da crítica da religião, da política utópica e da ascensão da burocracia, o que a psicanálise poderia oferecer? Nesse sentido, se voltarmos à pergunta sobre como sabemos que não estamos simplesmente diante da estilização de uma posição depressiva, deveremos insistir na relação entre ato e gozo. Pois o que leva a um ato dessa natureza, um ato para além do sentido, é a deslocalização e a despersonalização que a experiência de gozo necessariamente produz. Não poderia deixar de haver uma relação entre o ato e a tentativa de fazer do impossível do gozo a figura de uma forma de relação por vir. Por isso, na transferência não seria possível ao sujeito não ser impulsionado pela emergência do gozo para além das formas de inscrição simbólica do desejo. É exatamente isso que permite a liquidação da transferência, sua não consolidação em uma simples relação de sugestão e dependência.

Insistamos neste ponto: há uma emergência do caráter sem lugar do gozo no interior da transferência, como se vê por exemplo no gozo oral do paciente de Ernst Kris, assombrado pelo seu desejo de plágio e sua decomposição das ilusões de ser autor, ou no gozo do homem dos ratos diante da descrição das sevícias chinesas. A transferência, em sua suposição de saber, deve permitir a emergência de tal gozo, por mais que ele seja angustiante e desamparador. Mas ela deve permitir sua emergência não para assegurar o sujeito de que, afinal, seu gozo não é assim tão ameaçador, não para mostrar que há um lugar para ele na administração possível da vida tal como ela se dá na situação atual. Na verdade, a psicanálise tenta extrair desse gozo uma política, tenta mostrar como o caráter desamparador desse gozo traz em si uma verdade política, a saber, a verdade de que as condições de reprodução material da vida às quais o sujeito se submeteu só podem se exercer porque, desse gozo, ele não pode nada saber, com ele não é possível nada fazer, era necessário arruiná-lo e esquece-lo. Ou seja, o caráter sem inscrição, a natureza real desse gozo impulsiona transformações e produções singulares, isso se o sujeito for capaz de assumir, de produzir um ato que é a forma mesma da não inscrição. Nesse sentido, podemos entender melhor a 
importância de uma afirmação como: "o gozo é o que a verdade encontra ao resistir ao saber". ${ }^{14}$ Se ele é o que a verdade encontra ao resistir ao saber, então a deposição do sujeito suposto saber só pode ser feito em seu nome.

\section{Os paradoxos do passe}

Resta saber como se engendram, a partir daí, processos de reconhecimento em sua generalidade e universalidade suposta. Lacan procurou pensar tal engendramento através de suas discussões sobre o passe. Elas nos levam a problemas específicos de organização e transmissão, problemas esses que se mostrarão insolúveis dentro do horizonte lacaniano. O que leva Lacan a dissolver a própria instituição por ele criada, o próprio laço social por ele sustentado.

Lembremos como no interior do projeto da Escola havia a crença final no retorno a processos de reconhecimento baseados na assunção de certa forma de "comunicação". Nesse sentido, a Escola deveria ser o lugar no qual a liquidação da transferência poderia ser "comunicada": "esta experiência não pode ser eludida, seus resultados devem ser comunicados", dirá Lacan. ${ }^{15}$ Se os resultados devem ser comunicados, é porque o desvelamento do caráter sem-lugar do gozo que impulsiona a dejeção do analista e de seu saber suposto não leva a uma posição de simples isolamento. Dirá Lacan:

O que este passo, de ter sido feito só (seul), tem a ver com o único (le seul) que se acredita ser ao segui-lo? Não me fiaria eu à experiência analítica, ou seja, ao que me vem de quem se virou só? Acreditaria eu ser o único a te-la, então para quem eu falaria? ${ }^{16}$

Nesse contexto, Lacan fala de seu ato de fundação da EFP, mas é claro que se trata aqui também da natureza mesma do ato analítico. Ato que se faz só, mas que pode mesmo assim constituir um laço pressuposto nessa exigência de "comunicação". E há de sentir essa tensão extrema entre gozo e comunicação, uma tensão que talvez não possa ser de fato resolvida, que só poderia terminar na dissolução do espaço de comunicação, o que é outra maneira de compreender a questão da dissolução da Escola. Mas a dissolução do espaço de comunicação será, de forma paradoxal, a última aposta na possibilidade institucional da política. Uma instituição organizada como campo e turbilhão.

Lembremos aqui o que estava em jogo no dispositivo do passe. Segundo o procedimento do passe, um final de análise permite ao analisando "contar sua análise" a passantes que irão então passá-la a um júri. A primeira questão relativa a esse procedimento encontra-se na noção de "contar uma análise". Em outros momentos, Lacan falará de um ato que possa ser "legível" por todos. Mas que tipo de fala e de legibilidade integral é essa? O que se conta aqui? E para que forma de espaço comum? Pois percebamos a tensão real do problema. Há algo de transmissível no final de uma análise, mas como dirá Lacan: "como fazer reconhecer uma estatuto legal a uma experiência da qual não se sabe sequer responder?". ${ }^{17}$ Essa é uma maneira de se perguntar: como fazer reconhecer um gozo do qual a linguagem não quer e parece não pode nada saber? Lacan aposta 
em uma transmissão possível chegando mesmo a descrever aquilo que é integralmente transmissível, a saber, um matema, termo inspirado nos mitemas de Lévi-Strauss: unidades mínimas de articulação formal de relações pressupostas pelos mitos. Ou seja, a fala sobre a análise deveria ser a constituição de um matema capaz de passar a dois níveis de transmissão. O ato analítico parece se realizar na constituição de um matema.

De fato, só há comunicação se podemos falar em dois níveis de transmissão. Se conto algo para alguém e essa mesma pessoa não pode contar isso para uma terceira pessoa, não há comunicação alguma, pois não há garantia alguma de que o enunciado inicial foi, de fato, entendido. A comunicação demonstra que o sentido é a perpetuação da referência para além da modificação de seus enunciadores.

No entanto, a inscrição do ato em uma transmissão não deve ser sua submissão ao sentido, e nesse ponto encontra-se a complexidade da exigência. Podemos mesmo nos perguntar se isso não invalidaria necessariamente toda e qualquer comunicação. Lacan acredita que essa irredutibilidade do ato ao sentido é a única forma de garantir que não voltaremos a um "efeito de grupo". A associação entre "efeito de grupo" e "sentido" não poderia ser diferente. O que funda o grupo é a possibilidade da unidade da referência, é a partilha dos modos de interpretação de enunciados e práticas. O grupo é a expressão máxima da crença em uma gramática comum e a uma referência que não se transforma a partir da modificação dos seus enunciadores.

Por isso, podemos de fato nos perguntar se a experiência do passe poderia ter outro destino que o fracasso. Se o ato analítico modificação a relação entre sujeito e linguagem não é possível tentar recuperar níveis de comunicação após a liquidação da transferência. Essa experiência não se comunica, ela impulsiona a experiência da linguagem para além da comunicação. Pois a exigência de comunicação só pode ser realizada através da adequação do relato de sua análise às expectativas gramaticais e de codificação partilhadas previamente já que, em condição de comunicação, a linguagem é reiteração do código. A tendência necessária será de estereotipia dos relatos e conformação da singularidade destituinte do gozo ao discurso suportado pelo enunciador cujo nome próprio garante a sustentação identificatória do vínculo produzido pela Escola, seja esse nome próprio "Freud" ou "Lacan". Para uma teoria que vincula emancipação a destituição subjetiva, uma Escola "Freudiana" é uma contraditio in adjecto, da mesma forma que será uma contradição um campo "freudiano" ou um campo "lacaniano".

Entendamos o que leva Lacan a essa aposta no passe que não pode ser paga. $\mathrm{O}$ apelo lacaniano à legibilidade e à comunicação neste momento é sua forma de dizer: há algo no ato que tem força de implicação, ele dessupõe o saber mas não abole a relação social. O problema é efetivo, mas a resposta dada por Lacan através do passe só pode levar a um impasse, como o próprio Lacan acabará por perceber ao insistir, ao final, que deveríamos nos descolar da Escola. 
No entanto, esse impasse acaba por apontar algo de positivo em suas consequências políticas. Se o processo de emancipação política, processo esse do qual, à sua maneira, a experiência clínica faz parte, exige o reconhecimento de dessuposições de saber e de advento de novos homens e novas relações sempre enunciados no singular, então não cabe à teoria falar sobre como as relações por vir se darão. A antecipação teórica da reconciliação é uma atentado à própria reconciliação. O que a teoria pode fazer é defender a necessidade das transformações subjetivas que permitam aos sujeitos terem a força de revolucionar processos nas formas de vida. Mas ela não pode antecipar a forma e a direção das organizações e práticas que nascerão de tais transformações. Ou seja, a teoria pode falar sobre a forma dos processos de emergência de novos sujeitos, mas não pode falar da forma com que eles se organizarão após suas emergências, isto se quiser evitar o risco de fazer do futuro a mera imagem da realização das possibilidades imanentes ao presente. Neste ponto, a teoria deve parar a fim permitir à práxis realizar-se em suas múltiplas e inumeráveis configurações contextuais. Do contrário, ela se transforma em normatividade a impor sua imagem à práxis.

Longe de ser um mero enunciado negativo, ele nos lembra a exigência de organizações plásticas, capazes de se constituírem e de se destituírem em uma processualidade contínua a partir do reconhecimento de cada nova singularidade de gozo com a qual ela se confronta nos processos de liquidação da transferência. Esse talvez seja o sentido do abandono derradeiro de Lacan pela forma-Escola e da assunção de uma forma-campo baseada em conceitos como transitoriedade da existência do grupo, aleatoriedade das relações entre participantes, limitação dos processos de funcionamento burocrático e ausência de hierarquia.

\section{Notas}

1 Jacques Lacan, Autres écrits, p.262.

2 Ibidem, p.249.

3 Ibidem, p.252.

4 Ibidem, p.254.

5 Ibidem, p.332.

6 Ibidem, p.420.

7 Stalin, Marxism and linguistics (Disponível em: <www.marxism.org>).

8 Jacques Lacan, Seminário XX, p.26.

9 Ibidem, p.375.

10 Ibidem, p.426.

11 Jacques Lacan, Autres écrits, p.254.

12 Ibidem, p.334.

13 Ibidem, p.328. 
14 Ibidem, p.358.

15 Ibidem, p.255.

16 Ibidem, p.263.

17 Ibidem, p.262.

RESUMO - Trata-se de discutir aqui as implicações políticas dos conceitos de transferência, ato analítico e destituição subjetiva tais como elaborados por Lacan a partir dos anos 1960. Tais conceitos são peças fundamentais para uma reconfiguração da noção de emancipação política, o que evidencia uma dimensão fundamental da relação entre clínica e política.

Palavras-Chaves: Transferência, Ato analítico, Destituição subjetiva, Emancipação.

ABSTRACT - This article aims to discuss the political implications of the concepts of transference, analytical act and subjective destitution developed by Lacan in the 1960s. These concepts are decisive for a reconfiguration of the notion of political emancipation, evincing a major dimension of the relation between clinical practice and politics.

KEYWORDS: Transference, Analytical act, Subjective destitution, Emancipation.

Vladimir Safatle é professor do Departamento de Filosofia e do Instituto de Psicologia da Universidade de São Paulo. Autor, entre outros, de: Introdução a Jacques Lacan (Autêntica, 2017), O circuito dos afetos: corpos politicos, desamparo e o fim do indivíduo (Autêntica, 2016), Grande Hotel Abismo: para uma reconstrução da teoria do reconhecimento (Martins Fontes, 2012, versão em inglês pela Leuven University Press, 2016) e $A$ paixão do negativo: Lacan e a dialética (Unesp, 2006, versão francesa pela Georg Olms Verlag, 2010). @-vsafatle@yahoo.com

Recebido em 7.10.2017 e aceito em 22.10.2017.

I Faculdade de Filosofia, Letras e Ciências Humanas, Universidade de São Paulo, São Paulo, São Paulo, Brasil. 